Int. J. Electrochem. Sci., 13 (2018) 9942 - 9949

Short Communication

\title{
Investigation of Electrochemical Migration of Tin and Tin- Based Lead-Free Solder Alloys under Chloride-Containing Thin Electrolyte Layers
}

\author{
Shuyi Jiang ${ }^{1}$, Bokai Liao ${ }^{2, *}$, Zhenyu Chen ${ }^{2}$, Xingpeng Guo ${ }^{2}$ \\ ${ }^{1}$ School of Industrial Design, Hubei University of Technology, Wuhan 430068, China \\ ${ }^{2}$ Hubei Key Laboratory of Materials Chemistry and Service Failure, School of Chemistry and \\ Chemical Engineering, Huazhong University of Science and Technology, Wuhan 430074, China \\ *E-mail: bokailiao@yeah.net
}

doi: $10.20964 / 2018.10 .13$

Received: 13 June 2018 / Accepted: 15 July 2018 / Published: 1 September 2018

The electrochemical migration behaviors of pure tin and tin-based lead-free solder alloys under thin electrolyte layers containing chloride ions were investigated. Impacts of the applied bias voltage and thickness of electrolyte layer on the electrochemical migration processes were studied in detail. Results showed that the mean time to failure first increased and then decreased with increasing electrolyte- layer thickness. The maximum value of failure time was presented at a $200-\mu \mathrm{m}$-thickness. The higher bias voltage was applied, the faster rate of dendrite growth was. The migration element of tin-based lead-free solder alloys was tin and the formed dendrites displayed tree- and feather-like structures. Mechanisms relevant have been proposed to explain the electrochemical migration behaviors of tin and tin based solder alloys.

Keywords: Solder alloy; Corrosion; Electrochemical migration; dendrite

\section{$\underline{\text { FULL TEXT }}$}

(C) 2018 The Authors. Published by ESG (www.electrochemsci.org). This article is an open access article distributed under the terms and conditions of the Creative Commons Attribution license (http://creativecommons.org/licenses/by/4.0/). 